\title{
Health research prioritization: global and regional perspectives
}

Ahmed Mandil, ${ }^{1}$ Arash Rashidian ${ }^{2}$ and Rana Hajjeh ${ }^{3}$

${ }^{1}$ Coordinator Research and Innovation, Department of Science, Information and Dissemination, World Health Organization Regional Office for the Eastern Mediterranean, Cairo, Egypt. ${ }^{2}$ Director, Department of Science, Information and Dissemination, World Health Organization Regional Office for the Eastern Mediterranean, Cairo, Egypt. ${ }^{3}$ Director of Programme Management, World Health Organization Regional Office for the Eastern Mediterranean, Cairo, Egypt. (Correspondence to: Arash Rashidian: Rashidiana@who.int).

Citation: Mandil A; Rashidian A; Hajjeh R. Health research prioritization: global and regional perspectives. East Mediterr Health J. $2020 ; 26(3): 254-256$. https://doi.org/10.26719/2020.26.3.254

Copyright (c) World Health Organization (WHO) 2020. Open Access. Some rights reserved. This work is available under the CC BY-NC-SA 3.0 IGO license (https://creativecommons.org/licenses/by-nc-sa/3.o/igo).

The Eastern Mediterranean Region (EMR) is confronting unprecedented health challenges, exacerbated by demographic and epidemiologic changes, large burden of communicable and noncommunicable diseases, increasing health care costs, as well as the effects of contracted emergencies, social conflicts and massive population movements (1-3). These challenges have significantly impacted the delivery of health care services, but they have also affected the capacity of the Region to conduct health research. In order to improve the health status in the EMR, evidence-based policies are critical. In October 2019, the Eastern Mediterranean Regional Committee endorsed a resolution supporting the improvement of national institutional capacity for evidence-informed policy-making for health in all Member States (4-5). Research that focuses on the regional and national health priorities is essential to develop the evidence needed for region- and countryspecific solutions (6-7).

The World Health Organization (WHO) has identified four pillars as part of a comprehensive strategy that addresses research for health: 1) capacity building; 2) standards and governance; 3) translation of research to policy and practice; and 4) research priority setting (8). Priority setting helps to identify the resources needed for research, in particular as available resources are limited and waste cannot be afforded (9). Setting priorities for research can be a complex and tedious process. While different approaches to research prioritization exist, there is no clear consensus on what constitutes best practice (10-12).

Regardless of the approach followed, there are minimum criteria to be considered and followed in setting research priorities. When setting research priorities, countries and large institutions (including academic and research institutions) should follow approaches that take into consideration their needs and context (10). Furthermore, countries need to be aware of potential barriers to priority setting (e.g., linkage to identified national health priorities, involvement of stakeholders in the process, time and resources required for priority setting, and selection of appropriate priority setting approaches including reaching consensus among stakeholders). This includes barriers to implementing the identified priorities (e.g., proper dissemination of priorities to researchers and academic institutions, availability of human, logistic, and financial resources for research) (13).

There are different examples of research priority setting in the EMR (14-20). Despite these examples, a study of 10 Arab countries reflected various levels of development and resources in their national health research systems, while only three countries reported setting national health research priorities (21). While there may be a need for further national level action on identification of research priorities (21-22), there are questions on whether previous priority settings have resulted in affirmative action on guiding health research.

Asystematic review of health research priority settings in the Islamic Republic of Iran identified 36 studies, of which only one in four included an implementation plan (23). A recent study involving over 200 institutions in the EMR indicated that only half reported conducting research priority-setting exercises, of which only $40 \%$ followed a standardized approach and involved policymakers and stakeholders in setting such priorities. In addition, only a quarter of institutions reported that they examine the extent to which health policy-makers utilize research results, and a similar number reported measuring the impact of their health research $(22,24)$. Hence, there is still a misalignment between national health research priorities and actual research production and use (5). Examples of good practice, however, are abundant, including in emergency situations. While the world is coming to term on how to address the current COVID-19 pandemic (25), WHO has already rolled-out a global solidarity randomized controlled trial to find effective treatments for the disease. Similarly, a collective approach toward research priorities related to MERS-CoV was helpful in addressing some of the challenges caused by this regional and global concern (26-27).

Since 2016, the WHO Regional Office for the Eastern Mediterranean (WHO/EMRO) conducts in-house health research prioritization exercises every two years, following a two-round priority identification exercise, and uses the Nominal Group Technique for consensus development. Outcomes of such workshops are used to develop the Calls for Proposals for Research in Priority 
Areas of Public Health (RPPH) small grants and the Tropical Disease Research - Small Grant Scheme (TDRSGS). The current calls for proposals are now available on the WHO/EMRO website (http://www.emro.who.int/ index.html).

From WHO standpoint, research priority setting is a key action for enhancing research for health in the EMR in order to cover the gaps observed through research mapping activities (22,28-30). For example, while the region is disproportionately affected by emergencies, a bibliometric analysis of health research production in the EMR showed scarcity of published research on emergencies (30). WHO is keen to assist countries in strengthening their health research capacity and priority setting (8). In conclusion, health research priority setting assists researchers and policy-makers in conduct of research that has the greatest potential public health benefit and maximizes health equity. Priority setting should involve different stakeholders, including policymakers, which would increase the likelihood of the utilization of research evidence by different partners. Research priorities could also inform efforts beyond the health sector to better align research activities and funding with the evidence needs of decision-makers to achieve universal health coverage and health-related Sustainable Development Goals.

\section{References}

1. World Health Organization Regional Office for the Eastern Mediterranean (WHO/EMRO). EMR Vision 2023 Eastern Mediterranean Region. Cairo: WHO/EMRO; 2019 (http://www.emro.who.int/about-who/vision2023/vision-2023.html, accessed 10 March, 2020).

2. Al-Mandhari A. Public health in the Eastern Mediterranean Region: profound challenges, huge opportunities. Lancet. 2019 Sep 21;394(10203):992-993. DOI: 10.1016/So140-6736(19)32138-5.

3. Al-Mandhari A. Achieving "Health for All by All" in the Eastern Mediterranean Region. East Mediterr Health J. 2019 Oct 13;25(9):595-596. DOI: 10.26719/2019.25.9.595.

4. World Health Organization Regional Office for the Eastern Mediterranean. Developing national institutional capacity for evidence-informed policy-making for health. WHO Regional Committee Resolution. EM/RC66/R.5. Tehran, Islamic Republic of Iran, 14-17 October 2019 (http://www.emro.who.int/about-who/rc66/agenda.html).

5. Rashidian A, Mandil A, Mahjour J. Improving evidence informed policy-making for health in the Eastern Mediterranean Region. East Mediterr Health J. 2017;23(12):793-794. DOI: 10.26719/2017.23.10.793.

6. Editorial: The Bamako call to action: research for health. The Lancet 2008; 372(9653):1855. DOI: https://doi.org/10.1016/So1406736(08)61789-4

7. World Health Organization. Commission on social determinants of Heath: closing the gap in a generation. Geneva: World Health Organization; 2008.

8. World Health Organization. WHO strategy on research for health. Geneva: World Health Organization; 2009.

9. Chalmers I, Bracken MB, Djulbegovic B, Garattini S, Grant J, Gülmezoglu AM, et al. How to increase value and reduce waste when research priorities are set. Lancet. 2014;383:156-165, DOI: 10.1016/So140-6736(13)62229-1

10. Viergever RF, Olifson S, Abdul Ghaffar, Terry RF. A checklist for health research priority setting: nine common themes of good practice. Health Res Policy Syst. 2010;8(36):1-9.

11. Council on Health Research for Development (COHRED). Essential National Health Research and Priority Setting: Lessons Learned. Manila: COHRED, June 1997.

12. Fitch K, Bernstein SJ, Aguilar MD, Burnand B, LaCalle JR, Lazaro P, et al. The RAND/UCLA Appropriateness Method User's Manual. Santa Monica, CA: RAND Corporation; 2001.

13. Badakhshan A, Arab M, Rashidian A, Mehrdad N, Zendehdel K. Priority-setting in health research in Iran: a qualitative study on barriers and facilitators. Health Res Policy Syst. 2018;16(1):57. DOI: 10.1186/s12961-018-0313-1

14. Mendis S, Alwan A, (eds). Prioritized research agenda for prevention and control of noncommunicable diseases. Geneva: World Health Organization; 2011

15. McGregor S, Henderson KJ, Kaldor JM. How are health research priorities set in low and middle income countries? A systematic review of published reports. PLoS ONE 2014;9(10): e108787.

16. El-Jardali F, Makhoul J, Jamal D, Ranson MK, Kronfol NM, Tchaghchagian V. Eliciting policymaker' and stakeholders' opinions to help shape health system research priorities in the Middle East and North Africa region. Health Policy Plann. 2010;25:15-27.

17. Bigdeli M, Javadi D, Hoebert J, Laing R, Ranson K. Health policy and systems research in access to medicines: a prioritized agenda for low- and middle-income countries. Health Res Policy Syst. 2013;11:37

18. Zaidi S, Bigdeli M, Aleem N, Rashidian A. Access to essential medicines in Pakistan: policy and health systems research concerns. PLoS One. 2013 May 22;8(5):e63515

19. Gedik FG, Buchan J, Mirza Z, Rashidian A, Siddiqi S, Dussault G. The need for research evidence to meet health workforce challenges in the Eastern Mediterranean Region (Editorial). East Mediterr Health J. 2018;24(9):811-812. DOI: 10.26719.2018.24.9.811. 
20. Mansoori P, Majdzadeh R, Abdi Z, Rudan I, Chan KY, Iranian CHNRI Health Research Priority Setting Group. Setting research priorities to achieve long-term health targets in Iran. J Glob Health. 2018;8(2):020702. DOI: 10.7189/jogh.08.020702

21. Kennedy A, Khoja T, AbouZeid A, Ghannem H, IJsselmuiden C. National health research system mapping in 10 Eastern Mediterranean countries. East Mediterr Health J. 2008;14(3): 502-517

22. El-Jardali F, Mandil A, Jamal D, BouKarroum L, El-Feky S, Nour M, et al. Engagement of health research institutions in knowledge translation in the Eastern Mediterranean Region. East Mediterr Health J. 2018;24(7):672-679

23. Badakhshan A, Arab M, Rashidian A, Gholipour M, Mohebbi E, Zendehdel K. Systematic review of priority setting studies in health research in the Islamic Republic of Iran. East Mediterr Health J. 2018;24(8):753-769. DOI: 10.26719/2018.24.8.753

24. Mandil A, El-Jardali F, El-Feky S, Nour M, Al-Abbar M, Bou-Karroum L. Health research institutional mapping: an Eastern Mediterranean Regional perspective. East Mediterr Health J. 2018;24(2):189-197

25. Al Mandhari A, Samhouri D, Abubakar A, Brennan R. Coronavirus Disease 2019 outbreak: preparedness and readiness of countries in the Eastern Mediterranean Region. East Mediterr Health J. 2020;26(2):136-137. DOI: 10.26719/2020.26.2.136

26. Modjarrad K, Moorthy V, Ben Embarek P, van Kerkhove M, Kim J, Kieny MP. A roadmap for MERS-CoV research and product development: report from a World Health Organization consultation. Nat Med 2016;22(7):701-705 DOI: 10.1038/nm.4131

27. Malik MR, Mahjour J. Closing the knowledge gaps on MERS: three and half years since its detection, what have we learnt and what needs to be done urgently? East Mediterr Health J. 2015;22(2):85-86 (http://applications.emro.who.int/emhj/v22/02/ EMHJ_2016_22_02_85_86.pdf?ua=1\&ua=1).

28. World Health Organization Regional Office for the Eastern Mediterranean (WHO/EMRO). National health research system mapping in the Eastern Mediterranean Region. A study of ten countries. Cairo: WHO/EMRO; 2008.

29. Ghannem H, Becerra-Posada F, IJsselmuiden C, Helwa I, de Haan S. National research for health system mapping in 5 countries in the Eastern Mediterranean region and perspectives on strengthening the systems. East Mediterr Health J. 2011;17(3):260-110.

30. Tadmouri GO; Mandil A; Rashidian A. Biomedical and health research geography in the Eastern Mediterranean Region (20042013). East Mediterr Health J. 2019;25(10). 